\title{
Histomorphometric analysis of pulmonary vessels in single ventricle for better selection of patients for the Fontan operation
}

\author{
Marilyne Lévy, MD, PhDa \\ Claire Danel, $\mathrm{MD}^{\mathrm{b}}$ \\ Daniel Tamisier, MDa \\ Pascal Vouhé, MDa \\ Francine Leca, MDa
}

From the Service de Chirurgie Cardiaque, Hôpital Necker Enfants Malades, ${ }^{\mathrm{a}}$ and Service d'Anatomo-Pathologie, Hôpital Européen Georges Pompidou, ${ }^{\mathrm{b}}$ Paris, France.

Received for publication March 21, 2001; revisions requested May 11, 2001; revisions received June 25, 2001; accepted for publication Aug 9, 2001.

Address for reprints: Marilyne Lévy, MD, $\mathrm{PhD}$, Service de Chirurgie Cardiaque, Hôpital Necker Enfants Malades, 149 rue de Sèvres, 75015, Paris, France (E-mail: marilyne.levy@nck.ap-hop-paris.fr)

J Thorac Cardiovasc Surg 2002;123:263-70

Copyright @ $\odot 2002$ by The American Association for Thoracic Surgery

$0022-5223 / 2002 \$ 35.00+0 \quad \mathbf{1 2 / 1 / 1 1 9 6 9 7}$

doi:10.1067/mtc.2002.119697

Objective: In cases of single-ventricle physiology, the Fontan procedure often fails even when the usual selection criteria are strictly respected. We analyzed specimens from intraoperative open lung biopsies performed on 40 patients with single-ventricle physiology who were considered to be good candidates for the Fontan procedure. Histomorphometric study was performed to determine histologic factors predictive of failure of the Fontan procedure.

Methods: Histomorphometric studies were performed on samples from 40 patients aged 6 months to 23 years with single-ventricle physiology, either tricuspid atresia $(n=14)$ or univentricular heart $(n=26)$. The preoperative pulmonary arterial pressure was $18 \mathrm{~mm} \mathrm{Hg}$ or less in 35 cases and greater than $18 \mathrm{~mm} \mathrm{Hg}$ in 5 cases. Eighteen patients underwent total cavopulmonary connection, 16 patients underwent partial cavopulmonary connection, and 6 underwent a palliative procedure, as determined according to clinical and hemodynamic findings.

Results: Lung biopsy specimens from all 5 patients with pulmonary arterial pressure greater than $18 \mathrm{~mm} \mathrm{Hg}$ appeared abnormal, whereas they appeared abnormal only $51 \%$ of the time in the low pulmonary arterial pressure group. The most frequent histologic abnormality observed was extension of smooth muscle cells in the wall of distal intra-acinar pulmonary arteries. Of the 18 patients who underwent the Fontan procedure, 9 had normal distal pulmonary arteries and good surgical results (except 1 with the Fontan circulation taken down for an anatomic reason). The remaining 9 had thick-walled distal intra-acinar pulmonary arteries with poor results of the Fontan procedure, and 6 died. The mean percentage wall thickness of small intra-acinar pulmonary arteries was significantly greater among the patients with bad results than among those with good results of the procedure $(P<.01)$.

Conclusions: Lung biopsy specimens were abnormal in 51\% of patients with low pulmonary arterial pressure, there was no relationship between preoperative pulmonary arterial pressure and outcome, and extension of muscle in peripheral arteries was always present in cases of failure of the Fontan procedure. Histomorphometric study is therefore a useful adjunct to the usual selection criteria for surgical decision making in cases of single-ventricle physiology.

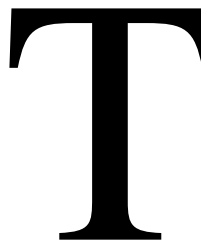

he Fontan operation has been demonstrated to benefit selected patients with tricuspid atresia, univentricular heart, and other complex congenital heart diseases. ${ }^{1-3}$ Initially, 10 inclusion criteria incorporating clinical, electrocardiographic, hemodynamic, and angiographic findings were proposed ${ }^{4}$; however, some of these criteria have been considered overly restrictive..$^{2,5-7}$ 
TABLE 1. Characteristics of patients

\begin{tabular}{|c|c|c|c|c|c|c|c|c|c|c|}
\hline \multirow[b]{2}{*}{ Case } & \multirow[b]{2}{*}{ Sex } & \multirow[b]{2}{*}{ Additional diagnosis } & \multirow[b]{2}{*}{ Previous operations } & \multirow[b]{2}{*}{ Age } & \multicolumn{6}{|c|}{ Catheterization results } \\
\hline & & & & & $\begin{array}{c}\text { PAP } \\
(\mathrm{mm} \mathrm{Hg})\end{array}$ & $\begin{array}{c}\text { PCP } \\
(\mathrm{mm} \mathrm{Hg})\end{array}$ & SAP & OP/OS & VEDP & $\mathrm{SaO}_{2}$ \\
\hline 1 & $\mathrm{~F}$ & TA, PS & APS & $6 y$ & 12 & & $100 / 60$ & 1 & 5 & $77 \%$ \\
\hline 2 & $\mathrm{M}$ & TA, PA & APS & $9 y$ & 13 & & $110 / 60$ & 1.3 & 8 & $78 \%$ \\
\hline 3 & $\mathrm{~F}$ & TA, PS & APS & $10 y$ & 20 & & $105 / 40$ & 1.1 & 6 & $77 \%$ \\
\hline 4 & $\mathrm{M}$ & TGA & PAB, PCPC & $3.5 \mathrm{y}$ & 11 & & $100 / 50$ & & 10 & $70 \%$ \\
\hline 5 & $\mathrm{~F}$ & TA, PS & None & $2 y$ & 13 & & $100 / 75$ & & & $74 \%$ \\
\hline 6 & $\mathrm{~F}$ & MA, TGA, PS & APS & $7 y$ & 17 & & $115 / 70$ & 2 & 10 & $80 \%$ \\
\hline 7 & $\mathrm{M}$ & TGA, MS & PAB & $18 \mathrm{mo}$ & 50 & & $90 / 70$ & & & \\
\hline 8 & $\mathrm{M}$ & levo-TGA, SAS & PAB, PCPC & $9 y$ & 13 & & $125 / 60$ & 0.6 & 6 & $76 \%$ \\
\hline 9 & $\mathrm{~F}$ & TA & PAB & $7 y$ & 16 & & $100 / 55$ & & 7 & $83 \%$ \\
\hline 10 & $\mathrm{M}$ & Corrected TGA, PS & APS & $11.5 \mathrm{y}$ & 14 & & $105 / 50$ & & 10 & $80 \%$ \\
\hline 11 & $\mathrm{~F}$ & $\begin{array}{l}\text { Ivemark syndrome, } \\
\text { AVSD, APVR }\end{array}$ & None & $6 \mathrm{mo}$ & 60 & 20 & $90 / 50$ & 1 & & $70 \%$ \\
\hline 12 & $\mathrm{~F}$ & TGA, MS, PDA & PAB, Blalock-Hanlon & $11 \mathrm{y}$ & 15 & & $130 / 80$ & & 7 & $71 \%$ \\
\hline 13 & $\mathrm{M}$ & levo-TGA, PS, MS & None & $7 y$ & 18 & 18 & $95 / 40$ & & 10 & $80 \%$ \\
\hline 14 & $\mathrm{M}$ & TA, PS & None & $3 y$ & 13 & & $110 / 65$ & 1.5 & 6 & $76 \%$ \\
\hline 15 & $\mathrm{~F}$ & TGA, PA & $\operatorname{APS}(\times 2)$ & $9 y$ & 20 & & & & 10 & $85 \%$ \\
\hline 16 & $\mathrm{~F}$ & PS & None & $16 y$ & 9 & & $120 / 70$ & 0.5 & 6 & $62 \%$ \\
\hline 17 & $\mathrm{~F}$ & TA, TGA, PS & None & $5 y$ & 18 & & $110 / 60$ & 1.5 & 10 & $75 \%$ \\
\hline 18 & $\mathrm{~F}$ & TGA & PAB, PCPC & $6 y$ & 13 & & $115 / 70$ & & & $85 \%$ \\
\hline 19 & $\mathrm{M}$ & TA, PS & APS & $7 y$ & 14 & & $100 / 55$ & & & $80 \%$ \\
\hline 20 & $\mathrm{~F}$ & TA, PA & APS & $11 \mathrm{y}$ & 15 & & $110 / 65$ & 2 & 6 & $78 \%$ \\
\hline 21 & M & PS & None & $15 y$ & 9 & & $120 / 60$ & 1.4 & 8 & $90 \%$ \\
\hline 22 & $\mathrm{M}$ & TA, PS & Waterston, APS (×2) & $16 y$ & 18 & 5 & $110 / 60$ & & 8 & $70 \%$ \\
\hline 23 & $\mathrm{M}$ & TA & PAB & $3 y$ & 14 & 5 & $95 / 60$ & & 8 & $65 \%$ \\
\hline 24 & $\mathrm{~F}$ & TGA, PS & $\operatorname{APS}(\times 2)$ & $4 y$ & 18 & 6 & $100 / 65$ & & 7 & $70 \%$ \\
\hline 25 & $\mathrm{M}$ & Azygos continuation, PS & $\operatorname{APS}(\times 2)$ & $7 y$ & 12 & & $100 / 55$ & & 13 & $79 \%$ \\
\hline 26 & $\mathrm{M}$ & TGA, SAS, PS & APS $(\times 2)$ & $11 \mathrm{y}$ & 13 & & $110 / 70$ & & 7 & $75 \%$ \\
\hline 27 & $\mathrm{~F}$ & TA, PS & None & $14 y$ & 14 & & $110 / 65$ & 0.8 & 7 & $74 \%$ \\
\hline 28 & $\mathrm{M}$ & TGA,PS & APS $(\times 2)$ & $22 y$ & 10 & & $120 / 60$ & 1.6 & 7 & $75 \%$ \\
\hline 29 & $\mathrm{~F}$ & TA, PS & None & $3 y$ & 12 & & $100 / 60$ & & 7 & $70 \%$ \\
\hline 30 & $\mathrm{M}$ & AVSD & PAB & $7 y$ & 16 & & $100 / 60$ & & 8 & $75 \%$ \\
\hline 31 & $\mathrm{M}$ & PS & None & $3.5 y$ & 12 & & $95 / 60$ & & 6 & $65 \%$ \\
\hline 32 & $\mathrm{~F}$ & PS & None & $13 y$ & 16 & & $110 / 65$ & 1.5 & 7 & $80 \%$ \\
\hline 33 & $\mathrm{M}$ & TA & PAB & $2.5 y$ & 10 & & $95 / 55$ & 0.5 & 6 & $70 \%$ \\
\hline 34 & $\mathrm{M}$ & TGA & PAB & $11 \mathrm{y}$ & 13 & 8 & $110 / 60$ & & 8 & $80 \%$ \\
\hline 35 & $\mathrm{~F}$ & PS & None & $6 y$ & 16 & & $100 / 60$ & & 10 & $85 \%$ \\
\hline 36 & $\mathrm{M}$ & PS & None & $5.5 \mathrm{y}$ & 16 & & $95 / 60$ & & 7 & $79 \%$ \\
\hline 37 & $\mathrm{~F}$ & PS & APS & $23 y$ & 10 & 10 & $130 / 70$ & & 10 & $82 \%$ \\
\hline 38 & $\mathrm{M}$ & PS & APS & $13 y$ & 20 & 18 & $110 / 65$ & & 5 & $60 \%$ \\
\hline 39 & $\mathrm{M}$ & PS & APS & $6 y$ & 18 & & $95 / 60$ & & 6 & $84 \%$ \\
\hline 40 & $\mathrm{M}$ & & PAB & $2 y$ & 15 & & $100 / 65$ & & 10 & $80 \%$ \\
\hline
\end{tabular}

$P C P$, Pulmonary capillary pressure; $S A P$, systemic arterial pressure; $Q P / Q S$, pulmonary to systemic perfusion ratio; VEDP, ventricular end-diastolic pressure; $T A$, tricuspid atresia; $P S$, pulmonary stenosis; $A P S$, aortopulmonary shunt; $P A$, pulmonary atresia; TGA, transposition of the great arteries; $P A B$, pulmonary artery banding; fen, fenestration; $M A$, mitral atresia; $N A$, not applicable; $M S$, mitral stenosis; $P D A$, patent ductus arteriosus; $S A S$, subaortic stenosis; $A V F$, arteriovenous fistula; $A V S D$, atrioventricular septal defect; $A P V R$, anomalous pulmonary venous return.

The outcome of this operation is highly dependent on several risk factors, among which pulmonary vascular resistances, ventricular end-diastolic pressure, and atrioventricular valve competence are the main determinants. In some cases, however, patients who were ideal candidates for the Fontan procedure have shown severe low cardiac output and marked accumulation of extravascular fluid resistant to medical treatment after this operation. Elevation of pulmonary 


\begin{tabular}{|c|c|}
\hline Outcome and $\mathrm{SaO}_{2}$ & Biopsy grade \\
\hline PCPC, $90 \%$ & 2 \\
\hline TCPC, $95 \%$ & 1 \\
\hline APS, $85 \%$ & 3 \\
\hline TCPC fen, 60 then $83 \%$ & 2 \\
\hline TCPC to PCPC, $80 \%$ & 3 \\
\hline TCPC, $100 \%$ & NA \\
\hline Atrial septectomy, $90 \%$, died & 3 \\
\hline AVF, $82 \%$ & 2 \\
\hline PCPC, $83 \%$ & 2 \\
\hline PCPC, $86 \%$ & NA \\
\hline PAB, APVR treatment, $80 \%$, died & 3 \\
\hline APS, $73 \%$ & 3 \\
\hline PCPC, atrial septectomy, $86 \%$ & NA \\
\hline TCPC to PCPC plus AVF, $85 \%$ & 1 \\
\hline PCPC, $80 \%$ & 2 \\
\hline TCPC fen, $65 \%$ then $95 \%$ & 1 \\
\hline TCPC fen, $85 \%$ & NA \\
\hline TCPC, $100 \%$ & 1 \\
\hline TCPC, $100 \%$ & NA \\
\hline TCPC fen, $86 \%$ & 1 \\
\hline PCPC, $90 \%$ & 2 \\
\hline APS, $85 \%$ & 2 \\
\hline TCPC to PCPC, 95\%, died & 3 \\
\hline TCPC to PCPC plus APS, $80 \%$, died & 3 \\
\hline PCPC, $82 \%$ & NA \\
\hline PCPC, $85 \%$ & 4 \\
\hline TCPC, $95 \%$ & 1 \\
\hline PCPC, $90 \%$ & 3 \\
\hline PCPC, $85 \%$ & 1 \\
\hline PCPC, $82 \%$ & 4 \\
\hline PCPC, $85 \%$ & NA \\
\hline TCPC fen, $90 \%$ & 2 \\
\hline PCPC, $87 \%$ & 1 \\
\hline PCPC, $80 \%$ & 1 \\
\hline PCPC, $88 \%$ & 2 \\
\hline PCPC, $86 \%$ & 1 \\
\hline TCPC to PCPC, died & 4 \\
\hline TCPC, died & 4 \\
\hline TCPC, died & 3 \\
\hline TCPC to PCPC, died & 3 \\
\hline
\end{tabular}

vascular resistances and ventricular failure are the most frequent causes of early death after the Fontan procedure, and attempts to take the Fontan circulation down at this stage are also associated with high mortality. ${ }^{8}$ Fenestration of the atrial baffle has been proposed as a way to reduce right atrial pressure, decreasing the incidence and the duration of pleural effusion and protein-losing enteropathy. ${ }^{9-11}$

Increased medial thickness can be found in patients with normal pulmonary arterial pressure (PAP) and resistance, and these changes could be responsible for high pulmonary arteriolar resistance in the postoperative period, leading in turn to Fontan procedure failure. ${ }^{12,13}$ Predicting pulmonary vascular structure from the hemodynamic data is difficult, however. ${ }^{14,15}$ Some authors have concluded that lung biopsy studies are of no benefit in decision making. ${ }^{16,17}$ In fact, they reported essentially modification of the proximal arteries and did not mention the status of distal intra-acinar small arteries. Therefore, lung biopsy specimens from patients with single ventricle and low pulmonary blood flow are often considered normal. Histomorphometric study of those arteries is important; indeed, even a slight increase of wall thickness of distal pulmonary arteries could be involved in the postoperative elevation of pulmonary resistance.

To improve the surgical management of total cavopulmonary connection (TCPC), we performed intraoperative lung biopsy on 40 patients with single-ventricle physiology and low pulmonary blood flow. We retrospectively analyzed the results of histomorphometric study of these biopsy specimens in relation to the outcome of the Fontan procedure to determine whether predictive factors could be established.

\section{Methods \\ Patient Selection}

Between 1992 and 1999 in Laennec Hospital, Paris, we obtained lung biopsy specimens from 40 patients aged 6 months to 23 years (mean $8.2 \pm 5.3$ years, median 7 years) with univentricular heart ( $\mathrm{n}$ $=26)$ or tricuspid atresia $(n=14)$. Clinical and hemodynamic data, surgical procedures, and outcomes are summarized in Table 1.

All patients underwent preoperative cardiac catheterization, and the interval between catheterization and lung biopsy was less than 1 month. Because pulmonary resistance could not be evaluated in all cases, we considered PAP and pulmonary blood flow.

In 38 cases the operation was determined on the basis of clinical and hemodynamic findings, and open lung biopsy was performed during the procedure. In the remaining 2 cases a preoperative lung biopsy was performed to help decide surgical management.

Eighteen patients underwent TCPC, fenestrated in 5 cases to facilitate the postoperative course, 16 patients had a partial cavopulmonary connection (PCPC), and 6 patients had a palliative procedure. Among the 18 patients who underwent a TCPC, 9 had a bad result, defined as either takedown of the Fontan circulation, low cardiac output, arterial oxygen saturation $\left(\mathrm{SaO}_{2}\right)$ less than $75 \%$ after a fenestrated Fontan operation, or death. All 18 patients underwent operation by the same surgical technique with anastomosis first between the superior vena cava and the right pulmonary artery and second between the inferior vena cava and left pulmonary artery. The myocardial protection and the aortic crossclamp time were comparable in all cases, and the postoperative 

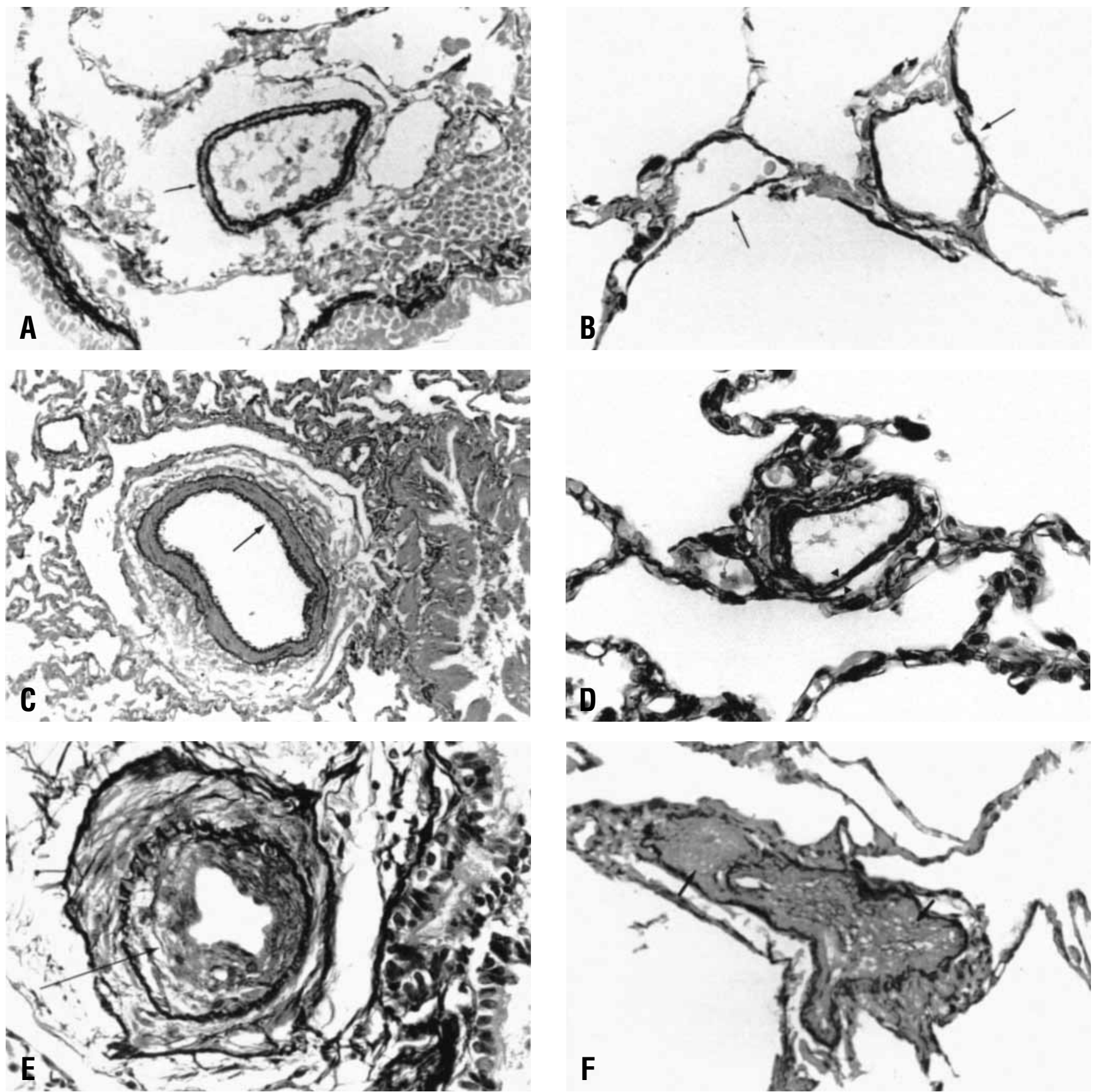

Figure 1. Light microscopy of lung biopsy specimens obtained during operation (modified orcein elastin stain, original magnification 400x). A, Normal terminal bronchial artery with thin and regular wall (arrow). B, Normal nonmuscularized alveolar duct artery (arrows). C, Terminal bronchial artery with mildly increased wall thickness without intimal damage (arrow). D, Extension of muscle in distal alveolar duct artery; note presence of muscle between laminae (arrowheads). E, Terminal bronchial artery with increased wall thickness and intimal fibrosis (arrow). F, Intimal fibrosis in lumen of alveolar duct artery (arrows).

management included pulmonary vasodilators, such as inhaled nitric oxide, and spontaneous breathing if possible. The fenestration of the Fontan procedure was chosen in the 5 last cases to facilitate the outcome.
Pathologic Analysis (Figure 1)

The lung biopsy specimens were taken when the lung was at least partially inflated and were fixed in $10 \%$ formaldehyde for 24 hours. Serial paraffin-embedded sections, 4- $\mu \mathrm{m}$ thick, were 
TABLE 2. Relationship of histologic evaluation of pulmonary arterial structure and preoperative PAP

\begin{tabular}{lccc}
\hline & & \multicolumn{2}{c}{ Histologic examination } \\
\cline { 3 - 4 } PAP $(\mathbf{m m ~ H g})$ & No. & Normal & Abnormal \\
\hline$\leq 18$ & 35 & $17(49 \%)$ & $18(51 \%)$ \\
$>18$ & 5 & 0 & 5 \\
\hline
\end{tabular}

stained with hematoxylin and eosin, the Perl stain for iron, and modified orceine for elastic fibers. In each biopsy specimen pulmonary vascular structure was analyzed with quantitative morphometric techniques as previously described ${ }^{18-20}$ : pulmonary arterial muscularity was assessed by determining the mean percentage arterial medial thickness of at least 40 arteries in different size ranges and compared with the normal profile for age. The proportions of muscular, partially muscular, and nonmuscular arteries accompanying terminal bronchioles, respiratory bronchioles, and alveolar ducts were also assessed to discover whether muscle had differentiated in more peripheral arteries than normal for age. In each biopsy specimen the sizes of the intra-acinar arteries were determined by measuring the external diameters of all arteries accompanying terminal bronchioles, respiratory bronchioles, and alveolar ducts and estimating the mean external diameter at each airway level.

Because the Heath-Edwards graduation is inappropriate in case of minor changes, the morphometric grades of lung biopsy specimens were assigned as follows: normal, normal arterial medial thickness of proximal and distal pulmonary arteries with no intimal damage (Figure 1, $A$ and $B$ ); grade 1, medial hypertrophy less than 2 times normal of proximal arteries but with normal medial thickness of distal arteries accompanying alveolar duct and alveolar wall (Figure 1, $C$ and $B$ ); grade 2, medial hypertrophy of proximal and distal pulmonary arteries less than 2 times normal (Figure 1, $C$ and $D$ ); grade 3, medial hypertrophy of proximal and distal arteries more than 2 times normal; and grade 4, intimal thickening (Figure 1, $E$ and $F$ ).

\section{Immunohistochemical Analysis (Figure 2)}

Serial paraffin sections of lung tissue were immunostained with antiserum to human smooth muscle $\alpha$-actin (DAKO Corporation, Carpinteria, Calif). Tissue sections were deparaffinized in toluene, rehydrated through graded concentrations of ethanol to water, and heated 40 minutes in buffered citrate at $\mathrm{pH}$ 6. Slides were incubated in hydrogen peroxide to block endogenous peroxidase activity, washed in Tris buffer saline solution, and incubated for 1 hour with antiactin (dilution 1:100) primary antibody or with normal serum used as a negative control. Sections were then incubated with a secondary antibody biotinylated immunoglobulin $\mathrm{G}$ and stained with streptavidin labeled with peroxidase. Slides were counterstained with Harris hematoxylin.

\section{Statistical Study}

Data are expressed as mean \pm SD. The significance of difference between groups was assessed by the Student $t$ test or the Fisher exact test, as appropriate.

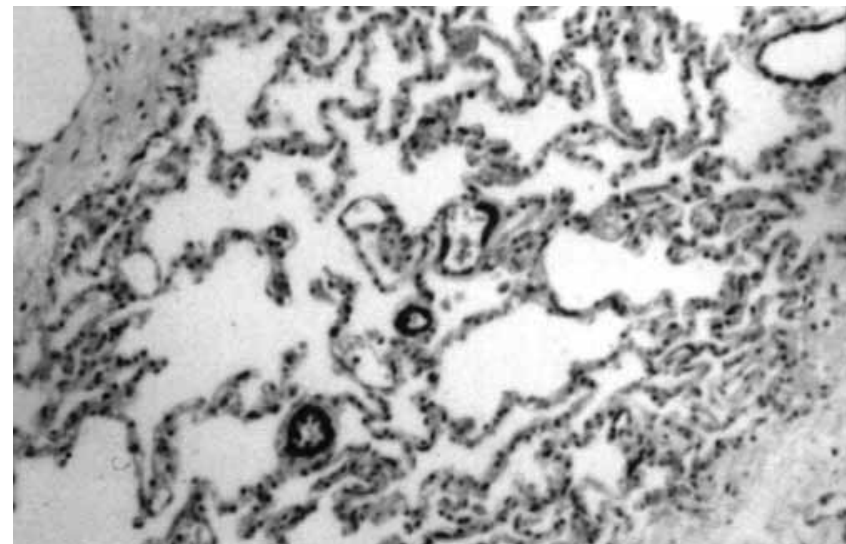

Figure 2. Smooth muscle $\alpha$-actin immunostaining of distal intraacinar pulmonary arteries with extension of muscle in peripheral arteries.

\section{Results}

To find a predictive factor, histologic findings were correlated against preoperative PAP and early postoperative outcome.

\section{Relationship of Histologic Pulmonary Arterial Structure and Preoperative PAP (Table 2)}

PAP was measured at preoperative cardiac catheterization in all cases. Five patients had a PAP greater than $18 \mathrm{~mm} \mathrm{Hg}$; these patients had a mean age of $6.8 \pm 5.5$ years. Thirty-five patients had a low PAP (mean $\leq 18 \mathrm{~mm} \mathrm{Hg}$ ); they had a mean age of $8.4 \pm 5.5$ years.

Lung biopsy specimens from all patients with a PAP greater than $18 \mathrm{~mm} \mathrm{Hg}(\mathrm{n}=5)$ were abnormal (1 grade 2, 3 grade 3 , and 1 grade 4 ). Proximal and distal arterial medial hypertrophy were present in all cases, and abnormally thickly walled interlobar veins were observed in 2 patients because of mitral stenosis or anomalous pulmonary venous return.

Among the patients with a PAP no greater than $18 \mathrm{~mm}$ $\mathrm{Hg}(\mathrm{n}=35), 17$ (49\%) had normal distal pulmonary arteries (normal or grade 1) and 18 had medial hypertrophy of proximal and distal arteries (8 grade 2, 7 grade 3, and 3 grade 4). Furthermore, the proportion of entirely muscularized arteries at each level was greater than expected for the age, indicating that muscle had differentiated in more peripheral arteries than normal, which was confirmed by the actin immunostaining (Figure 2). In this group of patients with low PAP there were no clinical or hemodynamic differences according to whether the biopsy specimen was considered normal or abnormal. Mean age, PAP, and $\mathrm{SaO}_{2}$ in those with normal and abnormal specimens were, respectively, $7.6 \pm 4$ versus $9.2 \pm 6.3$ years $(P=.4), 13.7 \pm 2.5$ versus $14 \pm 2.8 \mathrm{~mm}$ $\mathrm{Hg}(P=.7)$, and $76 \% \pm 6 \%$ versus $76.7 \% \pm 6.5 \%(P=.7)$. 


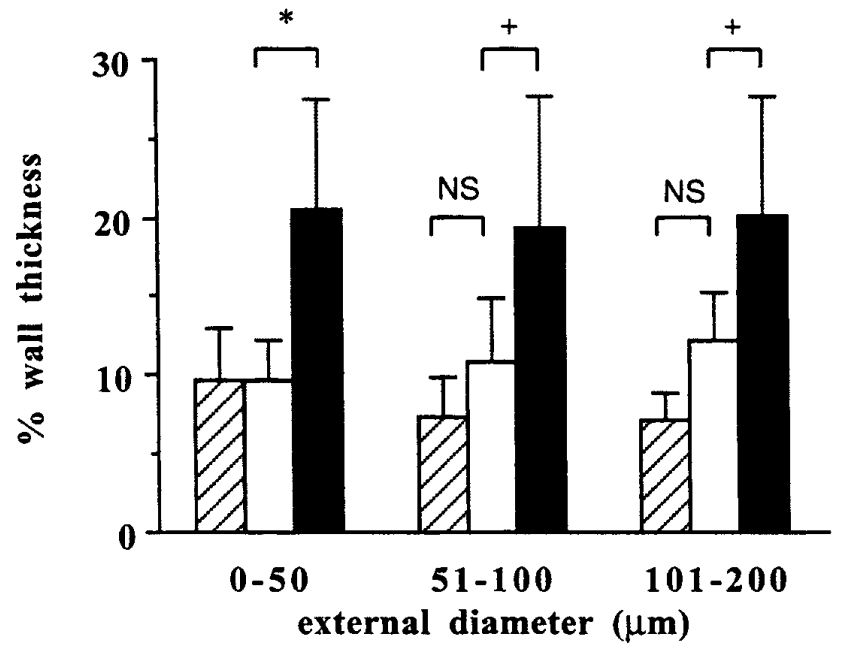

Figure 3. Relationship between percentage wall thickness of distal pulmonary arteries (external diameters $<50 \mu \mathrm{m}, \mathbf{5 0 - 1 0 0} \mu \mathrm{m}$, and 100-200 $\mu \mathrm{m}$ ) and outcome of Fontan procedure (striped bars, normal values for age; white bars, good result; black bars, bad result). NS, Not significant. Asterisk indicates $P<.01$; cross indicates $P<.05$.

We found anomalies even in the lung biopsy specimens from patients with high $\mathrm{SaO}_{2}$, which is considered a good indicator of low pulmonary resistance.

We found no differences in the previous surgical management that could explain those histologic changes. Indeed, among the 17 patients with normal distal arteries, 13 had pulmonary stenosis (6 previous aortopulmonary shunt) and 4 had no pulmonary protection, with banding at 1 month in 3 cases and at 6 months in the other. Among the 18 patients with biopsy specimens of at least grade 2,11 had pulmonary stenosis ( 7 with previous aortopulmonary shunt) and 7 had pulmonary hypertension with banding in the neonatal period. Furthermore, pulmonary arterial structure was histologically similar between patients with univentricular heart and those with tricuspid atresia.

The mean percentage medial thickness of distal intraacinar pulmonary arteries was significantly lower in patients with a PAP of $18 \mathrm{~mm} \mathrm{Hg}$ or less than in patients with a higher PAP $(P<.01)$. The difference was not significant for proximal intra-acinar pulmonary arteries (Table 3 ).

\section{Relationship of Histologic Pulmonary Arterial Structure and Early Outcome (Table 4)}

Among the 17 patients with normal distal intra-acinar pulmonary arteries (normal or grade 1 on histologic study) there were no deaths. There were 8 early deaths among the 23 patients with thick-walled distal pulmonary arteries (grade $\geq 2, P=.006$, Fisher exact test).

Among the total of 40 patients, 18 underwent TCPC and 22 underwent either PCPC or a palliative procedure. We
TABLE 3. Relationship of PAP and percentage wall thickness related to external diameter of intra-acinar pulmonary arteries

\begin{tabular}{lrccc}
\hline & & \multicolumn{3}{c}{ Percentage wall thickness } \\
\cline { 3 - 5 } & & Diameter & Diameter & Diameter \\
PAP $(\mathbf{m m ~ H g})$ & No. & $\mathbf{0 - 5 0} \mu \mathbf{m}$ & $\mathbf{5 1 - 1 0 0 ~} \boldsymbol{m}$ & $\geq \mathbf{1 0 1} \boldsymbol{\mu m}$ \\
\hline$\leq 18$ & 35 & $13.3 \pm 6.3^{*}$ & $16.1 \pm 7.8$ & $18.3 \pm 9.1$ \\
$>18$ & 5 & $22.2 \pm 6.9$ & $22.8 \pm 7.2$ & $23.5 \pm 4.2$
\end{tabular}

Data are mean \pm SD.

${ }^{*} P<.01$ compared with PAP $>18 \mathrm{~mm} \mathrm{Hg}$.

TABLE 4. Relationship of histologic evaluation of pulmonary arterial structure and outcome

\begin{tabular}{lcccc}
\hline & & \multicolumn{3}{c}{ Histologic examination } \\
\cline { 3 - 5 } Surgery & No. & $\begin{array}{c}\text { Normal or } \\
\text { grade 1 }\end{array}$ & $\begin{array}{c}\text { Grade 2 } \\
\text { or higher }\end{array}$ & Deaths* \\
\hline TCPC & 18 & 9 & 9 & $6(30 \%)$ \\
PCPC & 16 & 8 & 8 & 0 \\
Palliation & 6 & 0 & 6 & $2(33 \%)$
\end{tabular}

*All patients who died had abnormal biopsy specimens (grade 3).

concentrated on the TCPC group to determine factors predictive of failure of the procedure. Of the 18 patients who underwent TCPC, 9 had normal pulmonary biopsy specimens with thin-walled proximal and distal pulmonary arteries. In 8 of these cases the TCPC is working well with a follow-up from 1 to 8 years. In the other case the cavopulmonary connection was taken down for anatomic reasons. Nine patients who underwent TCPC had abnormal pulmonary biopsy specimens with medial hypertrophy of distal intra-acinar pulmonary arteries ( 2 grade 2 and 7 grade 3 ). Five patients had the TCPC taken down (with 4 deaths), 2 patients died of low cardiac output, and the 2 last patients are alive with fenestrated TCPC with bad early clinical results (pleural effusion and $\mathrm{SaO}_{2}<80 \%$ ). The biopsy specimens of the 6 patients who died were all grade 3 .

Among the patients who underwent TCPC, the mean percentage wall thickness of small intra-acinar pulmonary arteries was significantly greater in the 9 patients with poor surgical results than in those with good outcomes $(P<.01)$. There was no difference when only greater arteries were involved (Figure 3).

The mean age, PAP, hemoglobin level, and $\mathrm{SaO}_{2}$ were similar in the groups with good and bad results $(8.6 \pm 4.3 \mathrm{vs}$ $7.7 \pm 6.9$ years, $P=.5 ; 14 \pm 2.6$ vs $15 \pm 3 \mathrm{~mm} \mathrm{Hg}, P=.8$; $17.3 \pm 1.6$ vs $17.4 \pm 1.3 \mathrm{~g} / \mathrm{dL}, P=.76$; and $76.4 \% \pm 6.3 \%$ vs $74 \% \pm 8 \%, P=.15$, respectively). We found no significant difference in the previous surgical management that 
could explain the different outcomes of the Fontan procedure with respect to age and the degree of pulmonary vascular bed protection. Among the 9 patients with normal distal arteries and good outcomes, 8 had pulmonary stenosis (4 with previous aortopulmonary shunts, polytetrafluoroethylene 4- or 5-mm grafts, depending on age) and 1 had no pulmonary protection, with banding at 3 and 6 months. Among the 9 patients with thick-walled pulmonary arteries and poor outcomes, 5 had pulmonary stenosis (4 with previous aortopulmonary shunts) and 4 had pulmonary hypertension with banding at $1.5,2,3$, and 4 months. Two patients had persistence of high pulmonary blood flow after palliation (unprotective banding for 1 and large shunt for the other), and both of these patients had good outcomes after the Fontan procedure.

Sixteen patients underwent PCPC as the first stage of the Fontan procedure. Eight had normal pulmonary biopsy specimens and 8 had medial hypertrophy of proximal and distal pulmonary arteries (5 grade 2, 2 grade 3 , and 1 grade 4). There were no deaths in this group.

Six patients had a palliative procedure (1 pulmonary artery banding, 3 systemic-pulmonary anastomosis, 1 arteriovenous fistula, and 1 atrial septation). All these patients had abnormal pulmonary biopsy specimens (grade 2 or 3 ), and 2 died.

\section{Discussion}

The Fontan procedure was proposed for the correction of complex lesions where biventricular repair was impossible. In the absence of an effective right ventricle, even slight increases in pulmonary vascular resistance could result in low cardiac output, with extravascular fluid accumulation and hepatic congestion associated with increased early mortality. ${ }^{21-24}$ In our study and those of others, we noted failure of the Fontan procedure even when the usual selection criteria relying on hemodynamic data were strictly respected. We therefore looked at pulmonary vascular structure through a histomorphometric study of distal pulmonary vessels. Although a lung biopsy specimen may not represent the status of the whole lung because of the differential blood flows in the lungs of patients with single-ventricle physiology, it was always abnormal in cases of Fontan procedure failure.

\section{Relationship of Pulmonary Arterial Structure and PAP} Among the patients with a mean PAP greater than $18 \mathrm{~mm}$ $\mathrm{Hg}$, all had medial hypertrophy of proximal and distal arteries in the lung biopsy specimen. Among the patients with a mean PAP of $18 \mathrm{~mm} \mathrm{Hg}$ or less $(\mathrm{n}=35)$, only 17 patients had normal pulmonary arterial wall thickness; the remaining 18 had extension of muscle fibers in distal intra-acinar pulmonary arteries. No anatomic, clinical, or hemodynamic differences could be found to predict the histologic find- ings. This extension of muscle could be responsible for hypertensive pulmonary crisis. Indeed, small pulmonary arteries are involved in pulmonary resistance. The endothelial cells of those arteries produce vasodilatory factors, such as nitric oxide. In addition to its vasodilatory effects, nitric oxide acts as an anticoagulant and antiproliferative substance. $^{25}$ It has been shown in patients with pulmonary hypertension that it is in the small pulmonary arteries that the expression of the nitric oxide synthase is the least. ${ }^{26}$ In those resistive arteries the lack of nitric oxide could be responsible for a proliferation of smooth muscle cells in the wall of distal pulmonary arteries. The moderate increase in wall thickness of distal pulmonary arteries explains the normal PAP at catheterization but could also explain the pulmonary hypertensive crisis that we observed after cardiopulmonary bypass. Other authors have also noted similar discrepancies between pulmonary pressure and structure. ${ }^{14,16,27}$

We observed differences in medial hypertrophy at the preacinar and intra-acinar levels, as has already been described. ${ }^{16,28}$ In 6 children we found an increased medial thickness of proximal pulmonary arteries, whereas the distal pulmonary arteries accompanying the alveolar ducts and the alveolar wall were normal. All of these patients underwent TCPC with good early outcomes, except 1 whose TCPC was taken down for anatomic reasons. It therefore appears that the relationship between structure and pressure exists only when PAP is high $(>18 \mathrm{~mm} \mathrm{Hg}$ ) and that TCPC can be performed with good result when distal pulmonary arteries have a normal wall thickness.

\section{Relationship of Pulmonary Arterial Structure and Outcome (Morbidity and Early Mortality)}

All 8 children who died had abnormal pulmonary biopsy specimens (at least grade 3), and 5 of the 8 had a PAP of 18 $\mathrm{mm} \mathrm{Hg}$ or less. Of the 18 patients who underwent TCPC, $50 \%$ had good results. All of these had normal distal pulmonary arteries, associated in 6 cases with moderate medial hypertrophy of proximal pulmonary artery accompanying terminal bronchioles (grade 1). When increased medial thickness was also observed in distal intra-acinar pulmonary arteries in the lung biopsy specimen, the outcome of TCPC was always poor despite the usual postoperative management, including inhaled nitric oxide. We could not find other predictive factors (age, previous surgical management, degree of pulmonary vascular bed, surgical technique) that appeared to influence the outcome. Although lesions are potentially reversible, patients undergoing a procedure according to the Fontan principle can have perioperative acute vasoconstriction leading to labile hemodynamic values; this is often observed in the immediate postoperative period. ${ }^{29}$ The increased amount of pulmonary arterial smooth muscle contributes to the degree of pulmonary 
hyperreactivity produced by vasoconstrictive stimuli (hypoxia, cardiopulmonary bypass, and metabolic factors) present during the postoperative period.

There was no relationship between PAP and outcome among patients with low pulmonary pressures. Histologic anomalies were always associated with poor outcome of the TCPC even for patients with low pulmonary resistances.

Although the group of patients we studied was small, we found an apparent increased risk of death after physiologic repair among patients with univentricular heart with medial hypertrophy of small intra-acinar arteries. Furthermore, we demonstrated that moderate medial hypertrophy of pulmonary arteries accompanying terminal or respiratory bronchioles can be observed with normal wall thickness of distal pulmonary arteries accompanying alveolar ducts (grade 1) with good clinical results of TCPC. In contrast, even a slight increase of wall thickness of extremely distal pulmonary arteries (grade 2) leads to a complicated postoperative course, and all patients with histologic lesions more severe than grade 2 died or had the circulation taken down.

We conclude that histomorphometric study of distal intra-acinar arteries is useful in surgical decision making. Because such a study itself demands a surgical approach, the Fontan procedure should be performed in two stages, with lung biopsy during the first stage (the PCPC). The decision to complete the procedure should be made only in the absence of extension of muscle in more peripheral arteries than normal. This work warrants further investigation with a prospective study for a better selection of patients before the Fontan procedure.

\section{References}

1. Fontan F, Deville C, Quaegebeur J, Ottenkamp J, Sourdille N, Choussat A, et al. Repair of tricuspid atresia in 100 patients. J Thorac Cardiovasc Surg. 1983;85:647-60.

2. Mair DD, Rice MJ, Hagler DJ, Puga FJ, McGoon DC, Danielson GK. Outcome of the Fontan procedure in patients with tricuspid atresia. Circulation. 1985;72(3 Pt 2):II88-92.

3. Helgason H, Mayer JE, Sanders SP, Lang P, Jonas RA, Castaneda AR. Fontan operation for complex congenital heart defects other than tricuspid atresia [abstract]. Am Heart J. 1985;110:705.

4. Choussat A, Fontan F, Besse B, Vollot F, Chauve A, Bricand H. Selection criteria for Fontan's procedure. In: Anderson RH, Shineborn AE, editors. Pediatric cardiology, 1977. Edinburgh: Churchill Livingstone; 1978. p. 559-66.

5. Laks H, Milliken JC, Perloff JK, Hellenbrand WE, George BL, Chin A, et al. Experience with the Fontan procedure. J Thorac Cardiovasc Surg. 1984;88:939-51.

6. Dicarlo D, Marcelletti C, Nijveld A, Lubbers LJ, Becker AE. The Fontan procedure in the absence of interatrial septum. J Thorac Cardiovasc Surg. 1983;85:923-7.

7. Knott-Kraig CJ, Danielson GK, Schaff HV, Puga FJ, Weaver AL,
Driscoll DD. The modified Fontan operation: an analysis of risk factors for early postoperative death or take-down in 702 consecutive patients from one institution. J Thorac Cardiovasc Surg. 1995;109: 1237-43.

8. DeLeon SY, Ilbawi MN, Idriss FS, Muster AJ, Gidding SS, Berry TE, et al. Persistent low cardiac output after the Fontan operation: should takedown be considered? J Thorac Cardiovasc Surg. 1986;92:402-5.

9. Laks H, Pearl JM, Haas GS, Drinkwater DC, Milgater E, Jarmakano JM, et al. Partial Fontan: advantages of an adjustable interatrial communication. Ann Thorac Surg. 1991;52:1084-95.

10. Bridges ND, Mayer JE, Lock JE, Jonas RA, Hanley FL, Keane JF, et al. Effect of baffle fenestration on outcome of the modified Fontan operation. Circulation. 1992;86:1762-9.

11. Mertens L, Dumoulin M, Gewillig M. Effect of percutaneous fenestration of the atrial septum on protein-losing enteropathy after the Fontan operation. Br Heart J. 1994;72:591-2.

12. Kirklin JW, Barratt-Boyes BG. Cardiac surgery. New York: Wiley, 1986. p. $45,83-91$

13. Rabinovitch M, Sanders SP, Castaneda AR, Reid L. Morphometric analysis of lung biopsy tissue in candidates for Fontan-type procedure [abstract]. Am J Cardiol. 1981;47:447.

14. Juaneda E, Haworth SG. Double inlet ventricle: lung biopsy findings and implications for management. Br Heart J. 1985;53:515-9.

15. Yamaki S, Ajiki H, Haneda K, Takanashi Y, Ban T, Takahashi T. Pulmonary arterial changes in patients dying after a modified Fontan procedure following pulmonary artery banding. Heart Vessels. 1994; 9:263-8.

16. Geggel RL, Mayer JE Jr, Fried R, Helgason H, Cook EF, Reid LM. Role of lung biopsy in patients undergoing a modified Fontan procedure. J Thorac Cardiovasc Surg. 1990;99:451-9.

17. Caspi J, Coles JG, Rabinovich M, Cohen D, Trusler GA, Williams WG, et al. Morphological findings contributing to a failed Fontan procedure: twelve-year experience. Circulation 1990;82(Suppl):IV-177-82.

18. Haworth SG, Hislop AA. Pulmonary vascular development: normal values of peripheral vascular structure. Am J Cardiol. 1983;52:578-83.

19. Hislop AA, Reid L. Pulmonary arterial development during childhood, branching pattern and structure. Thorax. 1973;28:129-35.

20. Haworth SG, Reid L. A morphometric study of regional variation in lung structure in infants with pulmonary hypertension and congenital cardiac defect: a justification of lung biopsy. Br Heart J. 1978;40:825-31.

21. DeLeon SY, Ilbawi MN, Idriss FS, Muster AJ, Gidding SS, Berry TE, et al. Fontan type operation for complex lesions: surgical considerations to improve survival. J Thorac Cardiovasc Surg. 1986;92:1029-37.

22. de Vivie ER, Rupprath G. Long-term results after Fontan procedure and its modifications. J Thorac Cardiovasc Surg. 1986;91:690-7.

23. Mayer JE Jr, Helgason H, Jonas RA, Lang P, Vargas FJ, Castaneda AR. Extending the limits for modified Fontan procedures. $J$ Thorac Cardiovasc Surg. 1986;92:1021-8.

24. McAvoy MR, Fitzgerald E. Reducing multisystem failure after a Fontan procedure. Dimens Crit Care Nurs. 1988;7:19-26.

25. Moncada S, Palmer RM, Higgs EA. Nitric oxide: physiology, pathophysiology and pharmacology. Pharmacol Rev. 1991;43:109-42.

26. Giaid A, Saleh D. Reduced expression of endothelial nitric oxide synthase in the lungs of patients with pulmonary hypertension. $N$ Engl $J$ Med. 1995;333:214-24.

27. Juanada E, Haworth SG. Pulmonary vascular structure in patients dying after a Fontan procedure. Br Heart J. 1984;52:575-80.

28. Haworth SG. Pulmonary vascular disease in different types of congenital heart disease: implications for interpretation of lung biopsy findings in early childhood. Br Heart J. 1984;52:557-71.

29. Gale AW, Danielson GK, McGoon DC, Mair DD. Modified Fontan operation for univentricular heart and complicated congenital lesions. J Thorac Cardiovasc Surg. 1979;78:831-8. 